\title{
USING GIS MEASURES TO ANALYZE THE SPATIAL EQUITY TO PUBLIC PARKS IN LAHORE METROPOLITAN
}

\author{
Muhammad Ahmad Al-Rashid* \\ Muhammad Nadeem Rao** \\ Zeshan Ahmad***
}

\begin{abstract}
Public parks are considered as prime community assets that provide places for the citizens to enjoy and spend their leisure time. Parks can serve as the primary source not only incorporating physical activities, but also improving quality of life of residents. Equitable access to these services is one of the major concerns worldwide. However, a little attention is paid, in this regard, in the local context. This paper utilizes GIS tools and analyzes the equitable access to urban parks in the Lahore Metropolitan Area, with reference to its spatial distribution. The measures of access for the parks are computed for population, depending upon the type of facility at the administrative zone level. The accessibility to parks is measured using walking distance impedance and proximity analysis tool. The study further evaluates the spatial distribution of parks about population density and examines if differences are observed across different administrative zones in the Metropolitan. The least served areas and populations have been derived in spatial context across the study area. Moreover, maps prepared using hotspot analysis in GIS help to visually identify the spatial disparities and compare the differences among different administrative zones in the study area. It allows understanding of how different parks in the Metropolitan are distributed through space, and hence help in combating inequitable access. The results of this research can assist the planning authorities in identifying the spatial gaps in accessibility and addressing the needs for improving the accessibility to public parks across different zones in the Metropolitan.
\end{abstract}

Keywords: Administrative Zones, GIS, Lahore, Public Parks, Spatial Equity

\section{INTRODUCTION}

There has been an extraordinary development in urban populaces during the ongoing decades, and it is predicted that over seventy percent of the world's total population would be the part of urban areas by 2050 (UNFPA, 2011). This alarming urbanization statistic has raised worries about the growing detachment between urban occupants and habitat (Maller et al., 2009; Maruani and Amit-Cohen, 2007). Within many cities, especially in the developing world, spontaneous and casual settlements have brought about expanded spatial and social imbalance, asset misuse and ecological corruption (Wendel, Zarger and Mihelcic, 2012). The consistently diminishing green spaces have turned out to be inadequate to meet public demands regarding spatial dissemination, availability and the extent of the urban green land. Moreover, the modern urban communities aggravate the challenge of providing the growing need for green infrastructure within the wide range of contenting land uses (Wang et al., 2015). Thus, the issue of accessibility to urban green spaces is considered and discussed as a most growing concern in current sustainable urban planning agendas (Unal, Uslu and Cilek, 2016).

Planners perceived the significance of providing urban parks in the nineteenth-century (Nicholls, 2001 and 2004). Parks are vital in expanding chances to appreciate nature and to take part in recreational exercises. Parks can enhance the stylish and ecological character of urban situations, give open space to for entertainment and boost personal satisfaction for the inhabitants. These are seen as a method for particular sorts of refreshment of the psyche and nerves, which most city occupants extraordinarily require and are

* Muhammad Ahmad Al-Rashid, Lecturer, Department of City and Regional Planning, University of Management and Technology (UMT), Lahore, Pakistan.

Email Correspondence: ahmad.rashid@umt.edu.pk

** Muhammad Nadeem Rao, Assistant Director, Multan Development Authority, Multan, Pakistan. Email correspondence: raonadeemplanner@gmail.com

*** Zeshan Ahmad, Ph D. Student, Faculty of Business and Accountancy, University of Malaya, Malaysia. Email Correspondence: cva180042@siswa.um.edu.my 
vital to the decency of urban communities and their neighborhoods. An in-depth review of positive aspects of green infrastructure in metropolitan regions has been studied by numerous researchers (Bedimo-Rung, Mowen and Cohen, 2005; Chiesura, 2004). Their research covers a broad scope of recreational, mental, emotional, educational, social, financial, ecological, scientific and wellbeing related advantages. In this manner, urban parks are viewed as alluring parts and basal green framework of the metropolitan regions (Wolf, 2004). However, to encounter the advantages associated with public parks, residents must have reasonable and equitable access to these assets (Reyes, Páez and Morency, 2014).

Accessibility is one of the main variables affecting the regular utilization of urban green spaces and enhancing the general population's satisfaction (Bertram and Rehdanz, 2015; Cetin, 2015; La Rosa, 2014; Tu, Huang and Wu, 2018). Usually, accessibility can be defined as the ease with which an inhabitant can travel and reach the desired destination (Talen, 2003). As equality refers to treating every individual in the same manner. Equity also discusses the qualities of justice, fairness and considers the need of the inhabitants. Therefore, the term equity, rather than equality, is used in this paper to depict the fairness in the distribution of urban parks (Boone et al., 2009). Equity is profoundly associated with different dimensions of sustainability. Alongside economy and nature, equity shapes the three principal points on which a sustainable development, is based, these point are comprehended to be productive, green and reasonable (Campbell, 2003). Spatial equity is an essential proportion of sustainability, and along these lines, sustainable urban areas should try to have equal access to amenities and public facilities to all associates of their populace (Wilkinson and Pickett, 2011).

However, the equitable access to these utilities is challenging and requires in-depth analyses to distinguish the underserved zones, evaluate the impact of existing administrative policies, and encourage the most proficient method to assign rare public utilities (Tomic, Hewko and Hodgson, 2004). Without analyzing the spatial distribution, the usefulness of the public parks cannot be characterized accurately. Geographic Information Systems (GIS) has widely been applied for analyzing the spatial distribution and the extent to which the urban park's facility is equitable (Unal, Uslu, and Cilek, 2016; Tsou, Hung and Chang, 2005). The locational dimension in GIS is generally utilized to examine the accessibility to specific public infrastructure and utilities such as educational facilities, health care services, play areas and public parks (Macedo and Haddad, 2016). Since the late 1990s, innovations in GIS technology has tremendously developed several tools, such as network analysis, buffer analysis and Euclidian distance, that can perform advanced studies related to the spatial distribution of different public utilities (Unal, Uslu and Cilek, 2016). Regardless of the importance of this concept, the fair distributional access to public parks in urban communities has not been surveyed in developing countries like Pakistan.

Therefore, this study aims to investigate the spatial distribution and walking time accessibility of urban parks in the Lahore Metropolitan at the administrative zone level. The equitable access to parks is measured using walking time impedance and proximity analysis tool. The study further evaluates the spatial distribution of public parks about population density and examines the differences observed across different administrative zones in the Metropolitan. The least served areas and populations have been derived in spatial context across the study area. Additionally, the aim is to distinguish spatial and planning standards to give an ideal dimension of the use of open parks and to comprehend which zones are progressively appropriate to be tended to for new green spaces as proposed in the current Integrated Master Plan for Lahore Metropolitan.

\section{MATERIALS AND METHODS}

\section{Study Area}

Lahore District is one of the districts in Punjab province of Pakistan that contains the city of Lahore. The official boundary of Lahore comprises the total area of 1,77,200 hectares and is characterized by a flat terrain. It is situated in the northeast of Punjab close to the Indian border and extends from $74^{\circ} 10^{\prime}$ and $74^{\circ} 39^{\prime}$ E longitude and $31^{\circ} 15^{\prime}$ and $31^{\circ} 43^{\prime} \mathrm{N}$ latitude. Lahore is the second largest city of Pakistan in terms of population after Karachi and is the provincial capital of Punjab. In 1998, its population was recorded as 6.39 million which had increased to around eleven millions in 2017 (Pakistan Bureau of Statistics, 2017). Lahore was declared as the City District Government Lahore (CDGL) after promulgation of Local Government Ordinance in 2001. Initially, CDGL was divided into six administrative zones. Later in 2005, three more zones were added to CDGL. Now, Lahore City District comprises of one cantonment and nine administrative zones namely: Aziz Bhatti Zone, Data Ganj Bakhsh Zone, Iqbal Zone, Nishtar Zone, Ravi Zone, Shalimar Zone, Gulberg Zone, Samanabad Zone, and Wagha Zone. These Zones are further sub-isolated into 150 union councils (UCs) where the more significant part (122 UCs) are portrayed as urban, and the rest (28 UCs) are peri-urban/rural (Lahore Development Authority, 2004). Based on the administrative division system, union councils 
are the smallest administrative units. The detailed description and location of City District Lahore is shown in Figure 1.

Lahore is known for its cultural diversity and historical significance due to several monuments, gardens, and parks from the Mughal era. However, the rapid development in urban infrastructure in the Metropolitan, especially the increase in transportation and its vehicular emission, has changed the landscape of the city and such attractive places have been negatively affected (Abubakar, 2016). The current spatial distribution of public parks and gardens is analyzed where the administrative zone-level subdivisions are taken as the unit of analysis. This study relies on administrative boundary data and national census data available at the zone level.

\section{Data Processing}

The comprehensive data for the whole metropolitan is used in this study, and it came from several sources. First, digitized layers of the road network, land use data, TMA boundaries, public parks were initially obtained from the Lahore Development Authority (LDA), Parks and Horticultural Authority (PHA) and the Urban Unit, Lahore. In total, one thousand seventy two public parks were distinguished within the study area. Second, demographic data at TMA level was extracted from the Punjab Development Statistics 2015.

The whole dataset collected from different sources was incorporated in ArcGIS to rectify the topological errors. Using the edge-node topology for the roads, the geometric errors were removed through topological rules that represent the network properties. In the meantime, the road classification was separated into the primary, secondary, tertiary and local streets. Local and tertiary streets are the

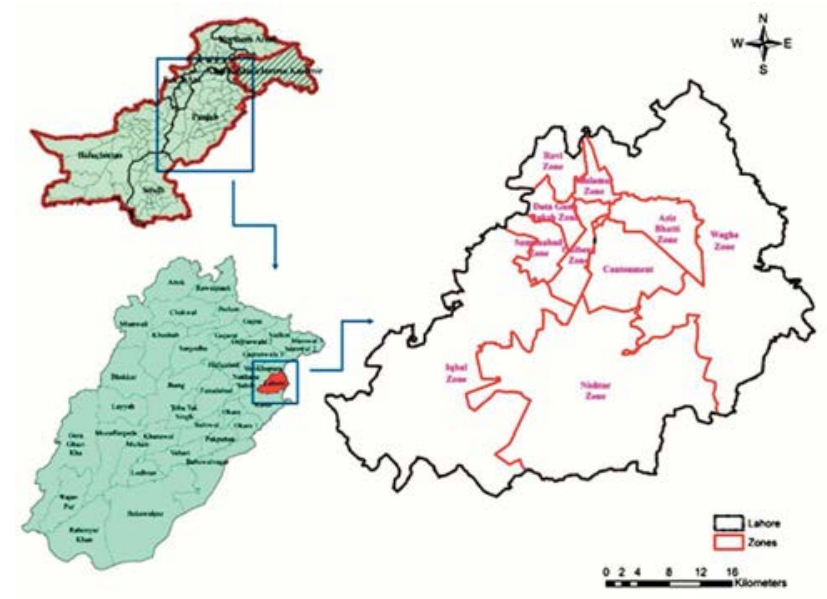

Figure-1: Indexed and Zone-level Map of City District Lahore. most straightforward class to experience for people on foot, while only vehicles can get on primary and secondary roads. The road network was prepared (Figure 2) in consideration of the Integrated Master Plan of Lahore (2008-2028) and Google Earth. Network Analyst tool in GIS was used to prepare the road network dataset. This dataset included the following attributes such as Fnode, Tnode, F and T minutes and one-way restriction to represent the real-time network linkage of the Lahore. The network dataset with edge nodes topology is shown in Figure 3.

\section{Study Methods}

The study utilizes and compares the accessibility of the public parks using walk time/distance impedance analysis. Using the walk time and distance impedance analysis, the

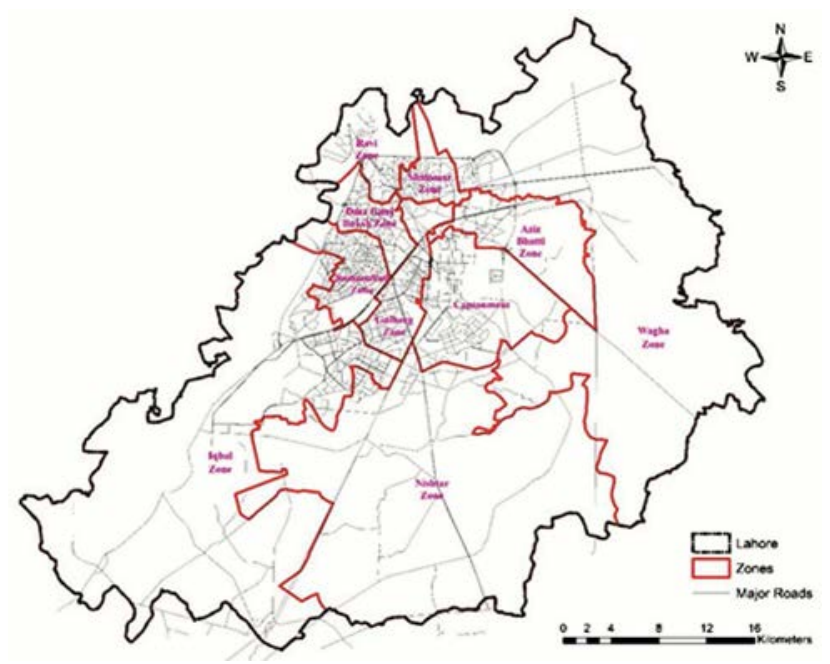

Figure-2: Major Road Network of Lahore.

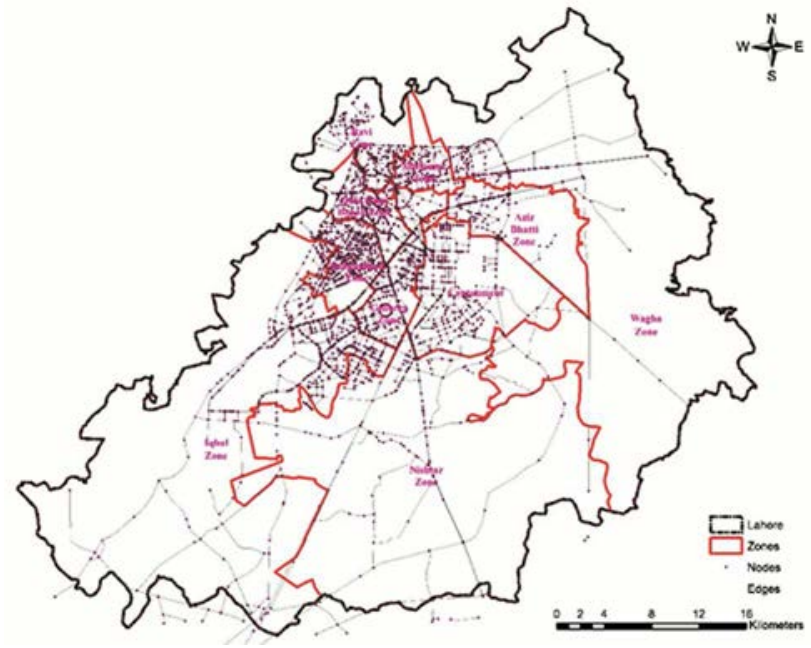

Figure-3: Network Dataset and Edge Note Topology Result. 
service area of the public parks along the network were derived. It indicates all the feasible streets that lie within the access of specified time and distance impedance. Setting the average walking speed at four hundred meters in five minutes, the study calculates the time level along the road network by this speed. Park accessibility is calculated with respect to time and distance. Travel time is calculated by using the formula Length of Road (S) = Travel Speed (v) $\mathrm{x}$ Walking Time ( $\mathrm{t}$ ). After populating the attributes with time and distance impedance, network dataset representing realtime network connections were built using Network Analyst Extension in ArcGIS 9.3 software. Thus, zones were divided into four categories with respect to time and distance, as given in Table 1.

All public parks were taken as the centers and buffers were established by the distance of each service level that the park can be reached in, using different time frames. Hence, using the point data in network analysis, service areas and accessibility zones were derived at, based on the different time impedances. Finally, the accessibility areas were derived at, and mapped using GIS hotspot analysis. Besides, the service areas were calculated in GIS by overlaying different database layers. For this, the population density at the zone level was derived from Punjab Development of Statistics reports, according to the following equation:

Population Density $($ Zone $)=($ Total Population of the Zone $)$ / (Total Area of the Zone)

It was assumed that the population is evenly distributed in the areas. Actually served population was calculated by multiplying the population density of the zone with the accessibility area of the park facilities. These served population and areas were further tabulated and compared across the City District among different zones, which helped to identify the gaps in the equitable provision of these facilities.

\section{RESULTS AND DISCUSSIONS}

Foremost, it was important to determine the land use of Lahore district. According to the Integrated Master Plan of Lahore, land use breakup is vibrant due to rapid change in

Table-1: Cagtegories of Accessibility Zones.

\begin{tabular}{|l|c|c|}
\hline Category & Time (Minutes) & Distance (Meter) \\
\hline Category-1 & $0-5$ & 400 \\
\hline Category-2 & $0-10$ & 800 \\
\hline Category-3 & $0-15$ & 1200 \\
\hline Category-4 & $0-20$ & 1600 \\
\hline
\end{tabular}

the uses. The total area of Lahore is about 177200 hectares. The ratio of parks and open spaces is reducing with respect to the area of other land uses. The total number of parks is 1072 in the whole city, which only contributes to $0.77 \%$ of the total area. Land use breakup of Lahore is given in Table 2 and the location of parks is given in Figure 4.

\section{Spatial Distribution of Public Parks}

Based on the methodology as discussed in the previous section, spatial accessibility of the urban parks in Lahore

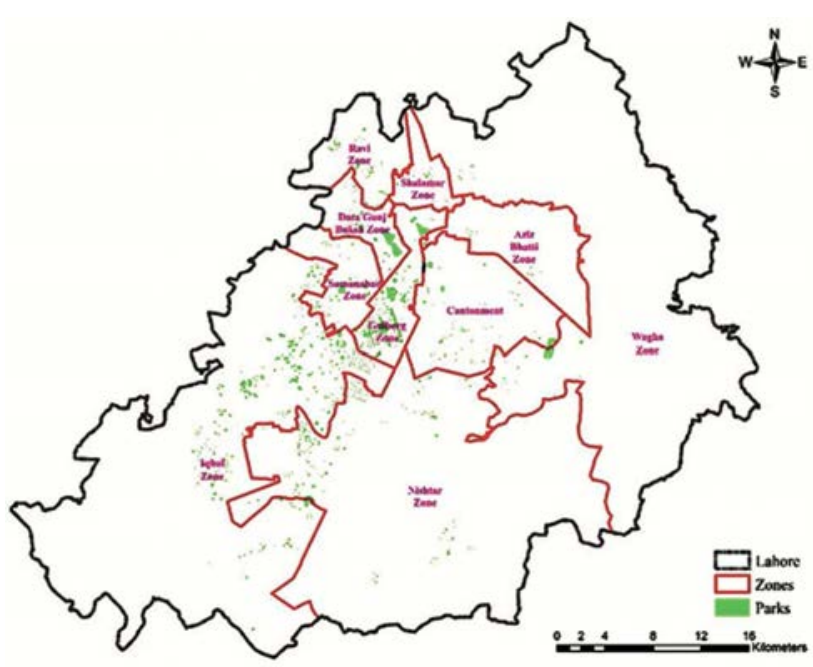

Figure-4: Location of Parks in Lahore.

Table-2: Land use breakup of Lahore.

\begin{tabular}{|l|c|c|}
\hline \multicolumn{1}{|c|}{ Land Uses } & Area (ha) & Persentage \\
\hline Residential & 27631.4 & 15.59 \\
\hline Commercial & 1288.34 & 0.73 \\
\hline Parks & 1370.23 & 0.77 \\
\hline Educational & 1321.68 & 0.75 \\
\hline Institutional & 561.55 & 0.32 \\
\hline Health & 261.16 & 0.15 \\
\hline Industrial & 2900.24 & 1.64 \\
\hline Graveyard & 312.06 & 0.18 \\
\hline Vacant/Agricultural & 125079.8 & 70.59 \\
\hline Water Bodies & 1716.25 & 0.97 \\
\hline Roads & 5490.29 & 3.10 \\
\hline Cantonment & 9267 & 5.23 \\
\hline Total & $\mathbf{1 7 7 2 0 0}$ & $\mathbf{1 0 0}$ \\
\hline
\end{tabular}


was derived. Spatial accessibility was derived based on the different categories of time impedances for every park present in Lahore. Figure 5 shows the served area of each park in the Metropolitan. The spatial distribution of the parks concerning the different walk time impedances, in each zone, can be seen.

Furthermore, the statistical analysis as shown in Table 3, reveals the comparison of the parks' service areas with the total served and unserved population in each administrative zone. The analysis provides a detailed description of service areas of parks according to selected walking time impedances. The total served population with different walking time impedance is also calculated. Table 3 also reveals the total unserved population in each administrative zone.

\section{Aziz Bhatti Zone}

Aziz Bhatti Zone is one of the municipalities of the Lahore metropolitan. It comprises of a total area of 9034 hectares, which is almost equivalent to $5.15 \%$ of the total area of the Metropolitan. The population density is seventy-five persons per square kilometer. According to the spatial distribution and statistical analysis, it contains only twelve public parks. The served area under accessibility zones of zero to five minutes walking time is 57.02 hectares out of 9034 hectares. Further, served area of accessibility Zones of zero to ten minutes, zero to fifteen minutes and zero to twenty minutes is 131.85 hectares, 257.15 hectares, and 612.71 hectares respectively. It is observed that 4304 people can access the parks in zero to five minutes of walking time. Also, the three other accessibility zones (i.e. zero to ten minutes, zero to fifteen minutes, and zero to twenty minutes walking time) are serving the $9,952,19,410$ and 46,249 people respectively. The total unserved area by parks in the Aziz Bhatti Zone is 8,521 hectares, which contributes to $93.2 \%$ of the total area. The total unserved population is 634,207 out of 689,456 . It reveals that $91.9 \%$ of the population in this zone is unserved by public parks (Figure 6).

\section{Data Gunj Buksh Zone}

Data Gunj Buksh Zone is the second densest administrative area of the Lahore metropolitan. The zone ranks third in the Metropolitan with a total population of $1,143,825$ residents. However, it is the second smallest zone with respect to the area in this region. According to the spatial distribution and statistical analysis, it contains of only seventy-seven public parks. The served area under accessibility zones of zero to five minutes is 451.15 hectares out of 3052 hectares. Further, served area of accessibility Zones of zero to ten minutes, zero to fifteen minutes and zero to twenty minutes is $1,055.84$ hectares, $1,512.38$ hectares and 2,283.36 hectares respectively (Figure 7).

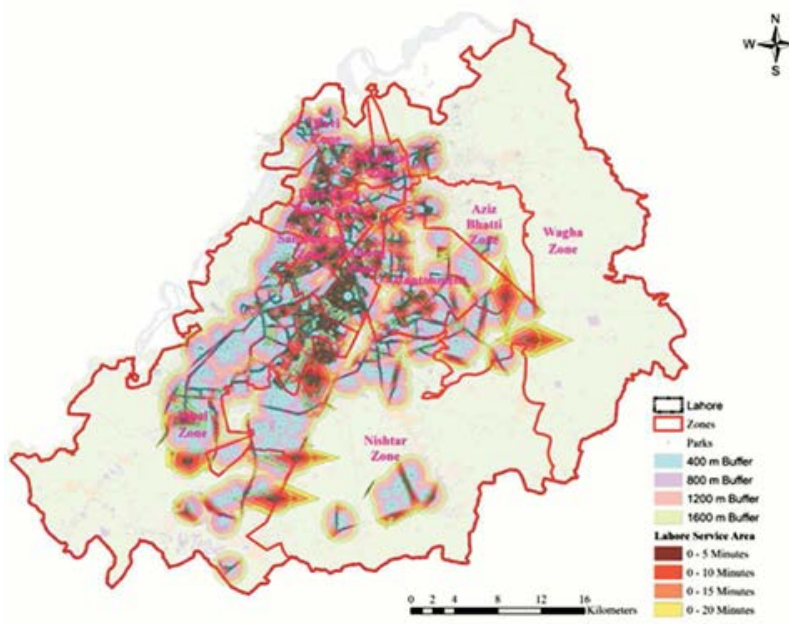

Figure-5: Spatial Distribution and Areas Served by Public Parks in Lahore Metropolitan.

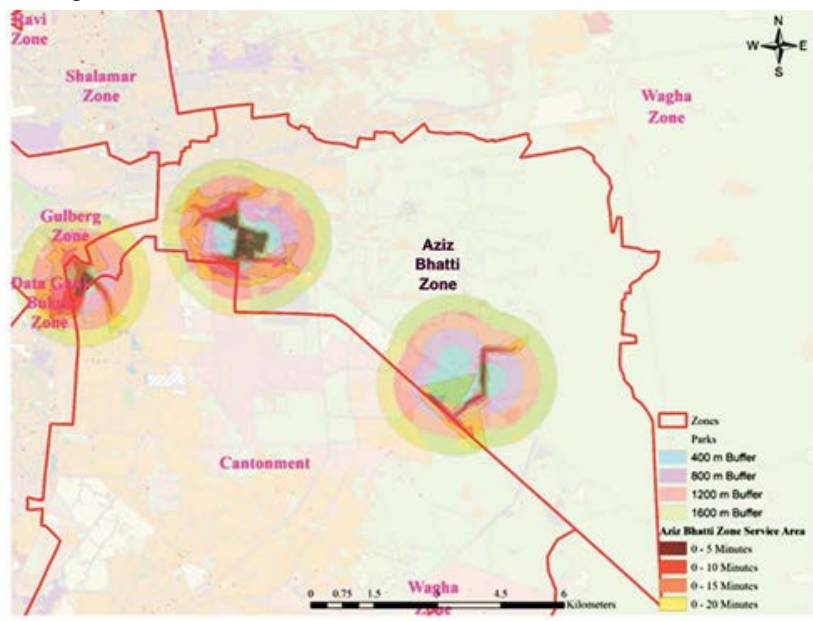

Figure-6: Spatial Distribution and Areas Served by Public Parks in Aziz Bhatti Zone.

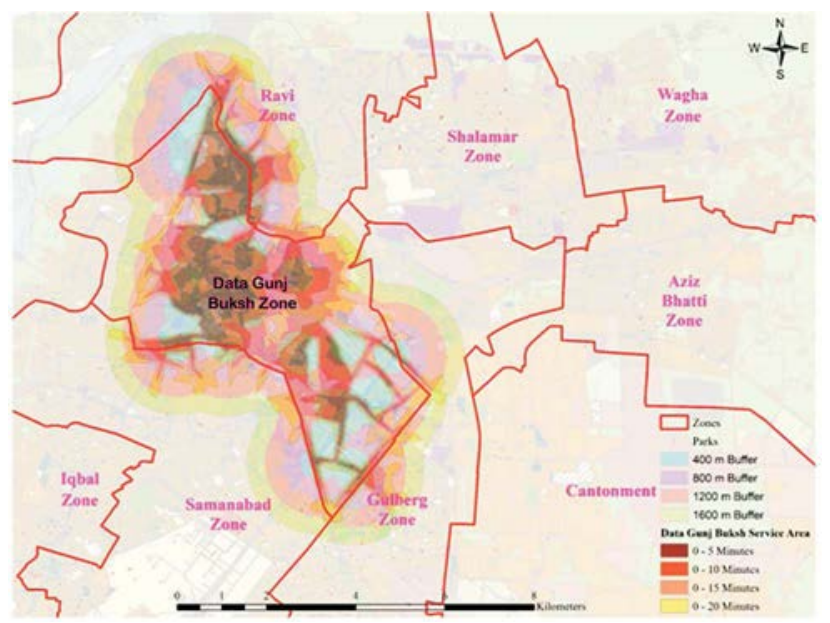

Figure-7: Spatial Distribution and Areas Served by Public Parks in Data Gunj Buksh Zone. 


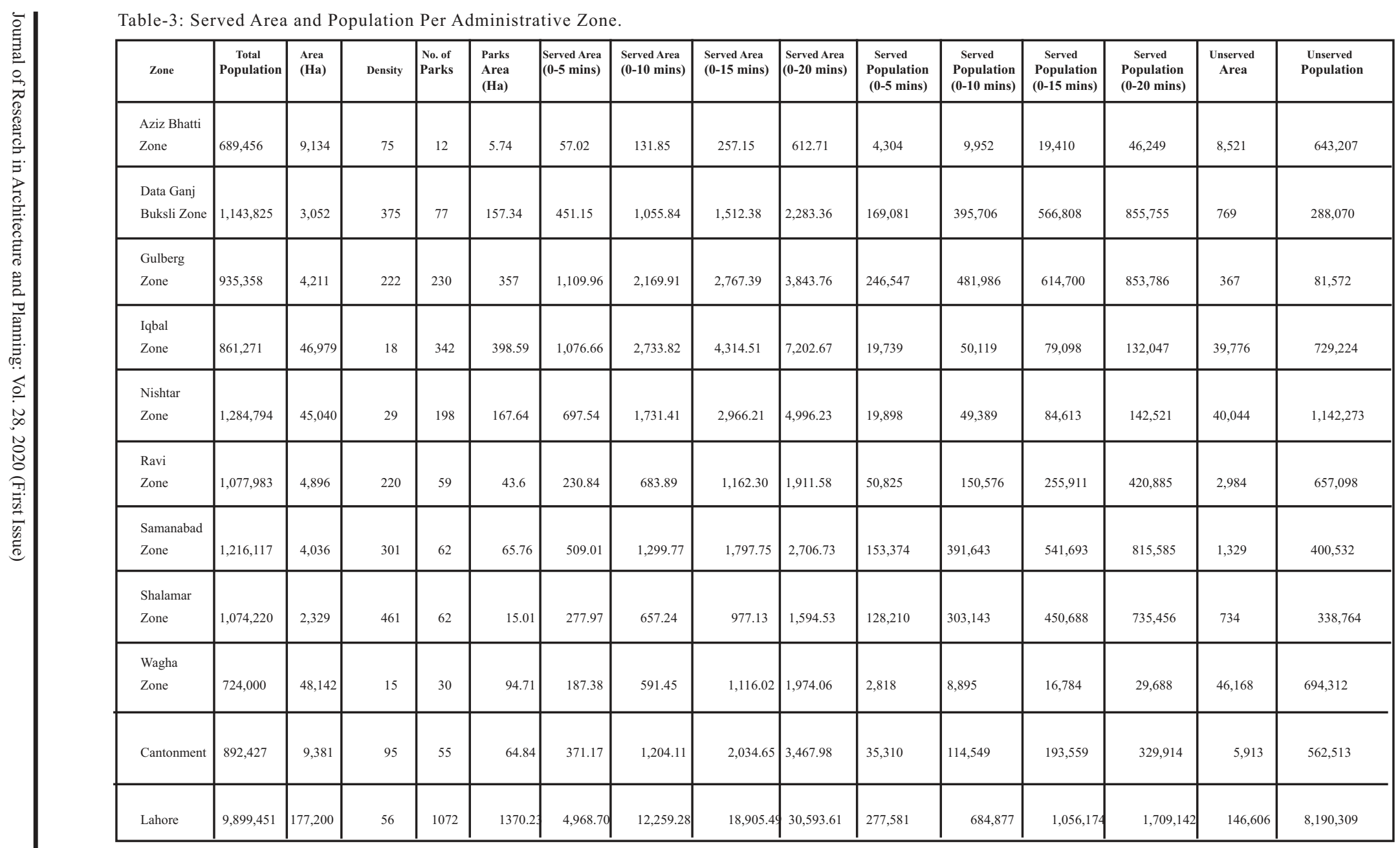


The accessibility zone of zero to five minutes is serving a population of 0169,081 out of $1,143,825$, which is equivalent to $14.7 \%$ of the total population. Also, three other accessibility zones are serving the population. The analyses reveal that $74.8 \%$ of the population can access public parks within a walking distance of twenty minutes. The total area unserved by the parks in the Data Gunj Buksh zone is 769 hectares, which contributes only $25.19 \%$ of the total area. Moreover, the total unserved population is 288,070 .

\section{Gulberg Zone}

Gulberg is one of the most advanced areas in Lahore and is developed largely as a commercial area. It comprises a total area of 4211 hectares with a population density of two hundred and twenty two persons per square kilometer. Gulberg is recognized as the land of flowers as many beautiful parks exist in this zone. It contains the second most number of parks after Iqbal Zone. These parks cover an area of 357 hectares. The served area under accessibility zone of zero to five minutes walking distance is 1109.96 hectares out of total 935,358 hectares of Gulberg zone. Further, served area of accessibility zones of zero to ten minutes, zero to fifteen minutes and zero to twenty minutes is 2,169.91 hectares, 2,767.39 hectares and 3,843.76 hectares respectively (Figure $8)$.

The total served population in accessibility zone of zero to five minutes walking distance is 246,547 . Analyses further revealed that a total of 853,786 people in this zone can access the public parks in twenty minutes of walking distance. The total unserved area by parks is only 367 hectares which is equivalent to $8.71 \%$ of the total area. Moreover, 81,572 people must walk for more than twenty minutes to access the public park in Gulberg. It can be argued that the public parks in the Gulberg zone are spatially better distributed as compared to other administrative zones.

\section{Iqbal Zone}

Iqbal Zone is a commercial and a residential locality in the south-western part of Lahore. It's extent is marked by Wahadat Road to the south and Multan Road to the northwest. It is the second-largest zone with respect to the area comprising of 46,979 hectares and a population of 861,271. Iqbal Zone is recognized as the second least dense area in Lahore having a population density of only eighteen people per square kilometer (Figure 9).

Statistical analyses reveal that the total served area under accessibility zones of zero to five minutes of walking distance

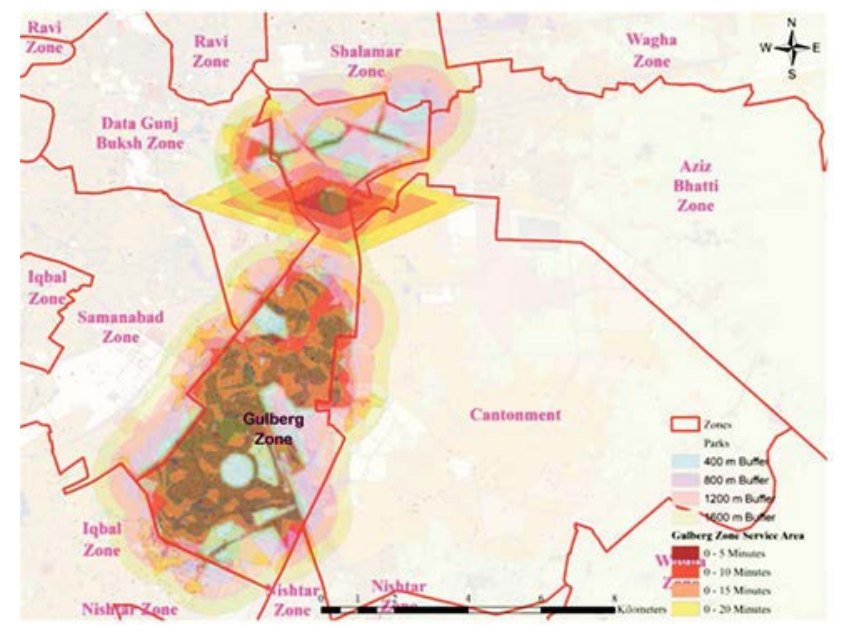

Figure-8: Spatial Distribution and Areas Served by Public Parks in Gulberg Zone.

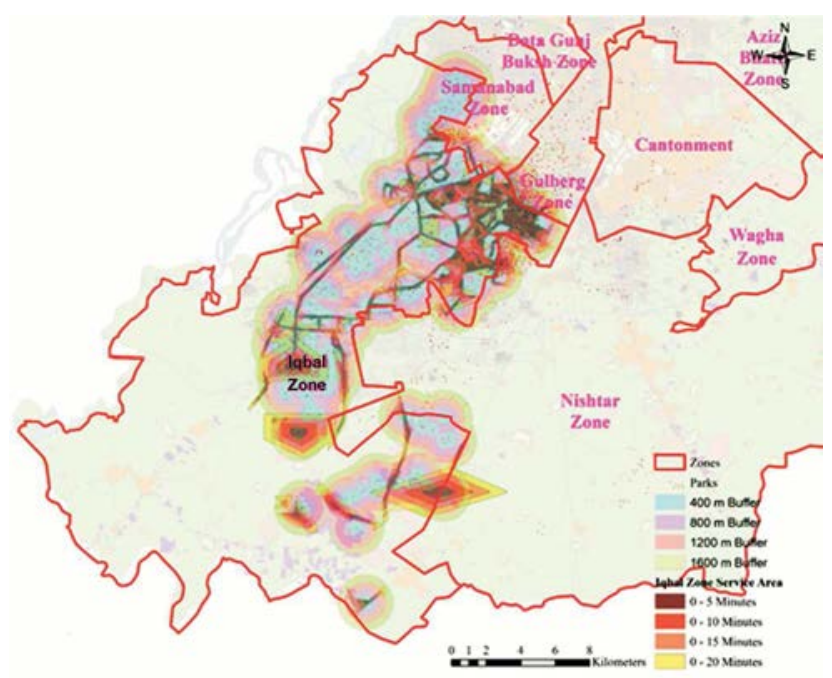

Figure-9: Spatial Distribution and Areas Served by Public Parks in Iqbal Zone.

is only $1,076.66$ hectares out of 46,979 hectares. While the served area of accessibility Zones of zero to twenty minutes of walking distance is 7,202.67 hectares. The accessibility zone of zero to five minutes is serving a population of 19,739 out of 861,271 , which means that only $2.29 \%$ of people in this zone can access the parks within five minutes of walking. While only $15.3 \%$ of people can reach the parks in twenty minutes of walking. The total unserved area by parks in the Iqbal zone is 39,776 hectares, which contributes $84.6 \%$ of the total area. Moreover, the total unserved population in this Zone is 729,224 . 


\section{Nishtar Zone}

Nishtar Zone is the third-largest administrative area in the Lahore metropolitan with a total population of 1,284,794. The Zone ranks first with respect to the population in the metropolitan area. According to the spatial distribution and statistical analysis, it contains one hundred and ninety eight public parks with a total covered area of 167.64 hectares (Figure 10).

The served area under accessibility zones of zero to ten minutes of walking distance is $1,731.40$ hectares out of 45,040 hectares. Further, the served area in accessibility zones of zero to twenty minutes of walking distance is 4,996.23 hectares. Table 3 further reveals that 49,389 people can access the parks in ten minutes of walking distance, while 142,521 people can access it in twenty minutes. However, $87.5 \%$ of people have to walk for more than twenty minutes to access the public park in this zone. The unserved area by parks in the Nishtar zone is 40,044 hectares which are equivalent to $88.9 \%$ of the total area.

\section{Ravi Zone}

Ravi Zone is one administrative zone in Lahore Metropolitan. The major part of this zone comprises of Shahdara, which is a populated and crowded area. It comprises a total area of 4896 hectares with a population density of two hundred and twenty persons per square kilometer. The zone contains fifty nine public parks, which cover an area of 43.6 hectares (Figure 11).

The served area under accessibility zone of zero to five minutes walking distance is 230.84 hectares out of total 4896 hectares of Ravi Zone. Furthermore, the served area of accessibility zones of zero to ten minutes, zero to fifteen minutes and zero to twenty minutes is 683.89 hectares, 1162.30 hectares, and 1911.58 hectares respectively. It was also analyzed that only $4.7 \%$ of the population can access the parks in five minutes of walking distance while $39 \%$ of people can access in twenty minute walk time. Moreover, 657,098 people must walk for more than twenty minutes to access the public park in this zone.

\section{Samanabad Zone}

Samanabad Zone is mixed land use locality in the northwestern part of Lahore. It comprises an area of 4036 hectares and a population of $1,216,117$. Samanabad is one of the densest areas of Lahore with a population density of three hundred and one people per square kilomter. The total

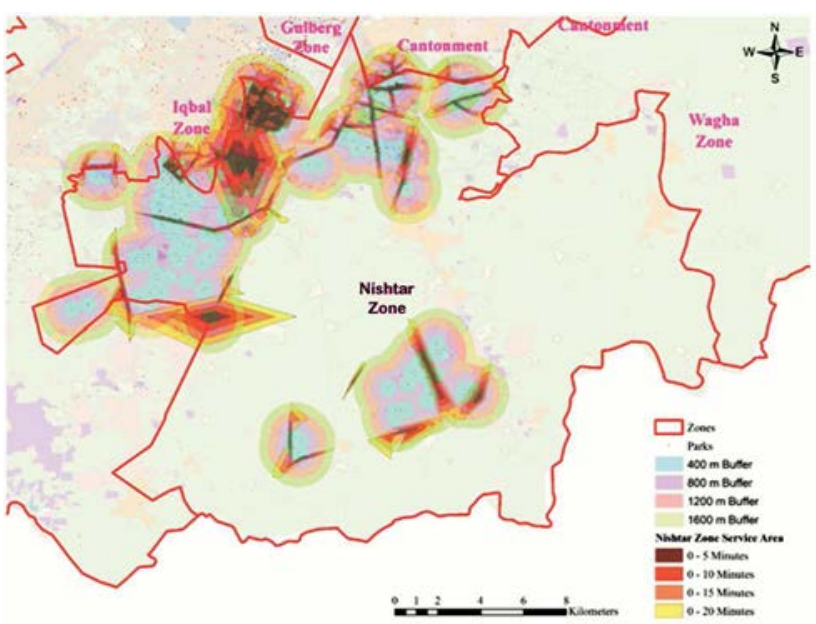

Figure-10: Spatial Distribution and Areas Served by Public Parks in Nishtar Zone.

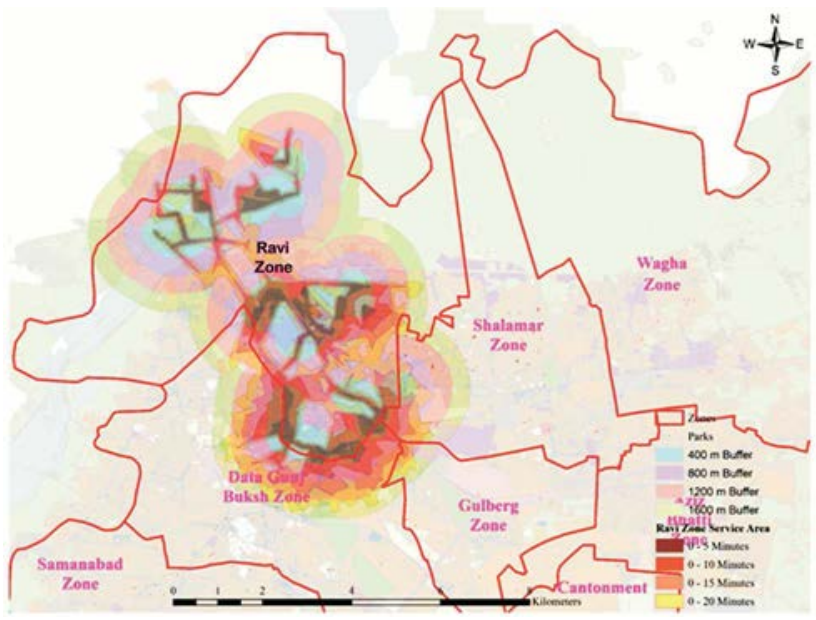

Figure-11: Spatial Distribution and Areas Served by Public Parks in Ravi Zone.

number of parks in this zone is sixty two which covers an area of 65.76 hectares (Figure 12).

Statistical analyses, as shown in Table 3, revealed that the total served area under accessibility zones of zero to five minutes of walking distance is only 509.01 hectares out of 4036 hectares. While the served area of accessibility zones of zero to twenty minutes of walking distance is 2706.73 hectares. The accessibility zone of zero to five minutes is serving a population of 153,374 , which means that only $12.6 \%$ of people in this zone can access the parks in five minutes of walking distance. While a major chunk (67\%) of the population can reach the parks in twenty minutes of walking distance. The total unserved area by parks in the Samanabad Zone is 1329 hectares which contributes $32.9 \%$ of the total area. Moreover, the total unserved population in this Zone is 400,532 . 


\section{Shalimar Zone}

Shalimar is one of the oldest administrative zones, located in the north of Lahore, along the historic Grand Trunk Road. Shalimar Zone is the smallest and the most congested zones in Lahore, with a population density of four hundred and sixty-one persons per square kilometer. There are only sixtytwo public parks available for 1,074,220 people. These parks cover an area of 15.01 hectares (Figure 13).

The served area under accessibility zone of zero to five minutes walking distance is 277.97 hectares out of total 2329 hectares of Ravi Zone. Further, served areas under accessibility zones of zero to ten minutes, zero to fifteen minutes and zero to twenty minutes are 657.24 hectares, 977.13 hectares, and 1594.53 hectares respectively. Further, it can be seen that only $11.9 \%$ of the population can access the parks in five minutes of walking distance while $68.2 \%$ of people can access in twenty minute walk time. Moreover, 338,764 people must walk for more than twenty minutes to access public parks in the Shalimar Zone.

\section{Wagha Zone}

Wagha Zone is situated in the northeastern part of Lahore along the India-Pakistan border. It is the largest administrative area in the Metropolitan but is the least dense zone. The population density is only fifteen persons per square kilometer. Moreover, the zone lacks the facility of public parks as compared to other zones. There are only fifteen public parks which cover an area of only 94.71 hectares (Figure 14).

The served area under accessibility zones of zero to twenty minutes of walking distance is only 1974.06 hectares which is only $4.10 \%$ of the total zone area. Table 3 further reveals that only 29,688 people can access the parks in twenty minutes of walking distance. However, $95.8 \%$ of people must walk for more than twenty minutes to access the public park in this zone. It is interesting to note that the total unserved area by parks in this zone is 46,168 hectares. Hence, the Wagha Zone possesses the least accessibility and poor spatial distribution of public parks.

\section{Cantonment}

Lahore Cantonment is regarded as an upscale neighborhood of the Metropolitan. It is an independent municipality, under the control of the Cantonments Department of the Ministry of Defense and Military Lands. Lahore Cantonment is located in the heart of the city neighboring Gulberg, Aziz Bhatti,

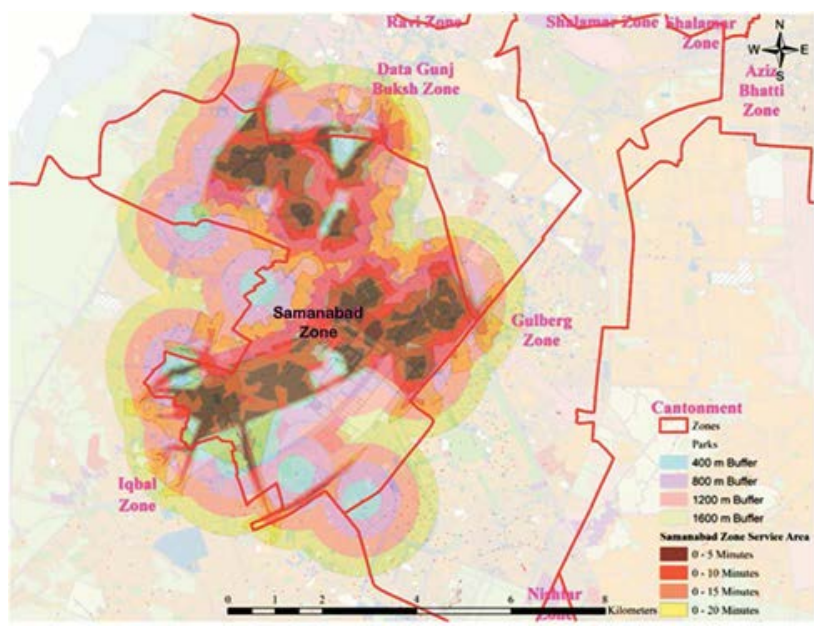

Figure-12: Spatial Distribution and Areas Served by Public Parks in Samanabad Zone.

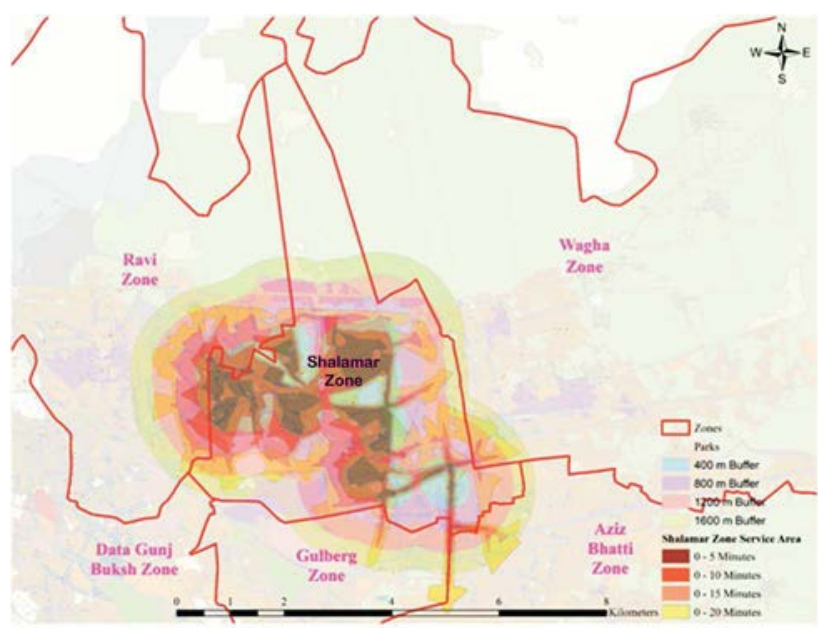

Figure-13: Spatial Distribution and Areas Served by Public Parks in Shalimar Zone.

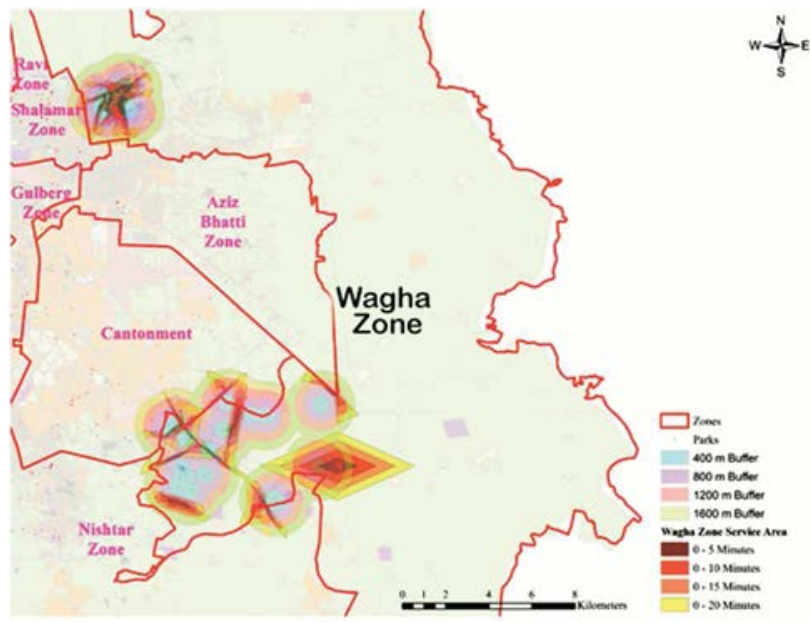

Figure-14: Spatial Distribution and Areas Served by Public Parks in Wagha Zone. 
Wagha, and Nishtar Zones. It comprises of a total area of 9381 hectares with a population density of ninety five persons per square kilometer. The zone contains fifty five public parks which cover an area of 64.84 hectares (Figure 15).

The served area under accessibility zone of zero to five minutes and zero to twenty minutes of walking distance is 371.17 hectares and 3467.98 hectares respectively. It is pertinent to note that only $3.9 \%$ of the population can access the parks in five minutes of walking distance, while $36.9 \%$ of people can access in twenty minute walk time. It infers that $63.03 \%$ of people must walk for more than twenty minutes to access the public parks in the Cantonment Zone.

\section{Overall Lahore Metropolitan}

The result, as shown in Table 3, reveals that the total area of the parks is 1370.23 hectares. There are 1072 parks in Lahore that contribute $0.77 \%$ of the total area of the Metropolitan, which reveals that the ratio of available public parks is far less than the standards. Four categories are developed to analyze the spatial distribution and access. The served area under accessibility zones of zero to five minutes of walking distance is 4968.70 hectares out of 177200 hectares. Further, served area under accessibility zones of zero to ten minutes, zero to fifteen minutes and zero to twenty minutes is $12,259.28$ hectares, $18,905.49$ hectares and 30,593.61 hectares respectively (Figure 5).

Further statistical analyses infers that a total of 277,581 people can access the public parks within walking distance of zero to five minutes, i.e. $2.80 \%$ people can access the public parks within zero to five minutes of walking distance. While only $17.1 \%$ population must walk for zero to twenty minutes to access the public parks in Lahore. The total unserved area by parks in Lahore is 146,606 hectares which contribute $82.7 \%$ of the total area. In a nutshell, it can be concluded that the public parks in Lahore are not equally distributed spatially. Besides, the provision and quantity of public parks are far below the standards.

\section{CONCLUSIONS AND RECOMMENDATIONS}

This study establishes the ability of GIS in assessing the existing facility of parks in Lahore. In GIS, Network service

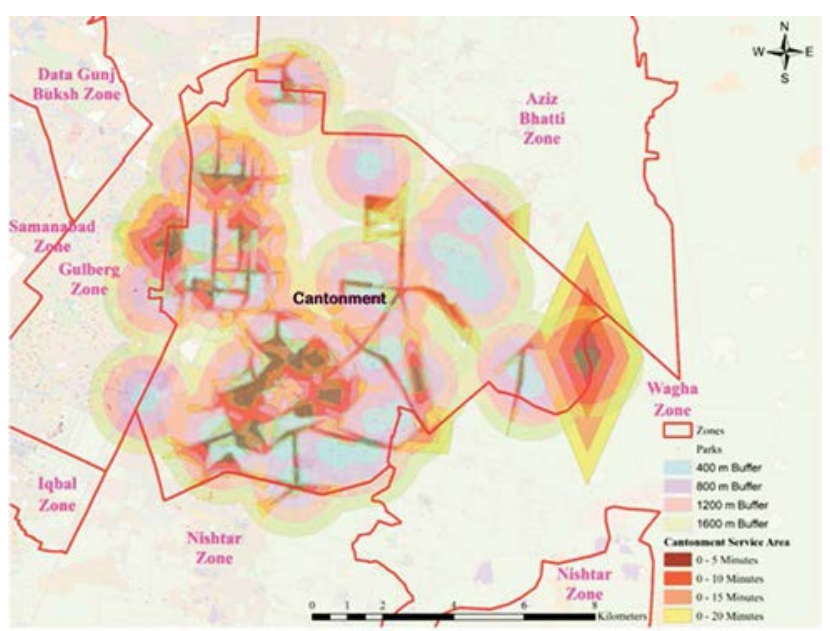

Figure-15: Spatial Distribution and Areas Served by Public Parks in Contonment Zone.

area analysis gives the best result to examine the accessibility of parks. This study concluded that more than $82 \%$ of the area and population remained unserved which shows the improper spatial distribution of existing parks in Lahore. The least served administrative area is the Wagha Zone, while the most served administrative area in Lahore is Gulberg Zone. The evaluation approach used in this study can be useful in understanding urban park spatial distribution and in developing successful urban park management policies. Realizing the results of this study, it is proposed that advanced techniques of GIS suitability combined with the Analytical Hierarchical Process (AHP) should be used to define new locations for public parks, keeping in view the existing spatial distribution pattern. Hence, results would be helpful to develop a more comprehensive strategy that can provide greater equitable distribution of public parks across different administrative zones in the Lahore Metropolitan.

\section{ACKNOWLEDGMENTS}

The authors would like to acknowledge the financial support provided by the Higher Education Commission (HEC) Pakistan for conducting this research. 


\section{REFERENCES}

Abubakar, S. M., 2016, "Lahore - A City of Gardens, Now a City of Concrete", Dawn News, viewed 22-03-2010, from https://www.dawn.com/news/1238407

Bedimo-Rung, A. L., Mowen, A. J. and Cohen, D. A., 2005, “The Significance of Parks to Physical Activity and Public Health: A Conceptual Model", American Journal of Preventive Medicine, 28(2): 159-168.

Bertram, C. and Rehdanz, K., 2015, “The Role of Urban Green Space for Human Well-being”, Ecological Economics, $12: 139-152$.

Boone, C. G., Buckley, G. L., Grove, J. M., and Sister, C, 2009, "Parks and People: An Environmental Justice Inquiry in Baltimore, Maryland", Annals of the Association of American Geographers, 99(4): 767-787.

Campbell, S., 2003, "Green Cities, Growing Cities, Just Cities? Urban Planning and the Contradictions of Sustainable Development", Journal of the American Planning Association, 62(3):126-132.

Cetin, M., 2015, "Using GIS Analysis to Assess Urban Green Space in Terms of Accessibility: Case study in Kutahya", International Journal of Sustainable Development and World Ecology, 22(5): 420-424.

Chiesura, A., 2004, "The Role of Urban Parks for the Sustainable City", Landscape and Urban Planning, 68(1): 129-138.

Lahore Development Authority (LDA), 2004, “Government of Punjab: Lahore Development Authority”, viewed 13-42019, from www.lda.com

La Rosa, D., 2014, “Accessibility to Greenspaces: GIS Based Indicators for Sustainable Planning in a Dense Urban Context”, Ecological Indicators, 42: 122-134.

Macedo, J. and Haddad, M. A., 2016, "Equitable Distribution of Open Space: Using Spatial Analysis to Evaluate Urban Parks in Curitiba, Brazil", Environment and Planning B: Planning and Design, 43(6): 1096-1117.

Maller, C., Townsend, M., St Leger, L., Henderson-Wilson, C., Pryor, A., Prosser, L. and Moore, M., 2009, "Healthy Parks, Healthy People: The Health Benefits of Contact with Nature in a Park Context", Paper presented at the The George Wright Forum.

Maruani, T. and Amit-Cohen, I., 2007, “Open Space Planning Models: A Review of Approaches and Methods”, Landscape and Urban Planning, 81(1-2): 1-13.

Nicholls, S., 2001, "Measuring the Accessibility and Equity of Public Parks: A Case Study Using GIS", Managing Leisure, 6(4): 201-219.

Nicholls, S., 2004, "Measuring the Impact of Parks on Property Values: New Research Shows that Green Spaces Increase the Value of Nearby Housing", Parks and Recreation, 39(3): 24-32.

Pakistan Bureau of Statistics, 2017, "Provisional Summary Results of 6th Population and Housing Census 2017, Islamabad", viewed 13-01-2019, from http://www.pbscensus.gov.pk/content/block-wise-provisional-summary-results-6th-populationhousing-census-2017-january-03-2018.

Reyes, M., Páez, A., and Morency, C., 2014, "Walking Accessibility to Urban Parks by Children: A Case Study of Montreal”, Landscape and Urban Planning, 125: 38-47.

Talen, E., 2003, "Neighborhoods as Service Providers: a Methodology for Evaluating Pedestrian Access", Environment and Planning B: Planning and Design, 30(2): 181-200.

Tomic, S. K. E., Hewko, J. N. and Hodgson, M. J., 2004, "Spatial Accessibility and Equity of Playgrounds in Edmonton, Canada", Canadian Geographer/Le Géographe Canadien, 48(3): 287-302.

Tsou, K.-W., Hung, Y.-T. and Chang, Y.-L., 2005, “An Accessibility-based Integrated Measure of Relative Spatial Equity in Urban Public Facilities", Cities, 22(6): 424-435. 
Tu, X., Huang, G. and Wu, J., 2018, “Contrary to Common Observations in the West, Urban Park Access Is Only Weakly Related to Neighborhood Socioeconomic Conditions in Beijing, China", Sustainability, 10(4): 1115.

Unal, M., Uslu, C. and Cilek, A., 2016, "GIS-Based Accessibility Analysis for Neighbourhood Parks: The Case of Cukurova District", J. Digit. Landsc. Archit, 1: 46-56.

UNFPA, 2011, “State of World Population 2011: People and Possibilities in a World of 7 Billion”, Tech. Rep. 2011 UNPF Rep.

Wang, D., Brown, G., Liu, Y. and Mateo-Babiano, I., 2015, “A Comparison of Perceived and Geographic Access to Predict Urban Park Use", Cities, 42: 85-96.

Wendel, H. E. W., Zarger, R. K. and Mihelcic, J. R., 2012, “Accessibility and Usability: Green Space Preferences, Perceptions, and Barriers in a Rapidly Urbanizing City in Latin America”, Landscape and Urban Planning, 107(3): $272-282$.

Wilkinson, R. and Pickett, K., 2011, “The Spirit Level: Why Greater Equality Makes Societies Stronger”, USA, Bloomsbury Publishing.

Wolf, K. L., 2004, "Public Value of Nature: Economics of Urban Trees, Parks and Open Space", Paper presented at the Design with Spirit: Proceedings of the 35th Annual Conference of the Environmental Design Research Association, D. Miller and JA Wise, Environmental Design Research Association. 